Journal of

Women's Health and Gynecology

\title{
Prevalence and Factors Associated with Violence against Women in Pakistan
}

\section{Narjis Rizvi ${ }^{* 1}$, Anam Feroz ${ }^{2}$, Saba Pervez ${ }^{3}$, Oyinlola Oyebode ${ }^{4}$}

1,2,3 The Aga Khan University - Department of Community Health Sciences, Stadium Road, PO Box 3500, Karachi 74800

${ }^{4}$ Warwick Medical School, CAHRD, University of Warwick

${ }^{\star}$ Corresponding author: Narjis Rizvi, The Aga Khan University - Department of Community Health Sciences, Stadium Road, PO Box 3500, Karachi 74800, E-mail: narjis.rizvi@aku.edu

Received Date: September 04, 2019 Accepted Date: October 10, 2019 Published Date: October 12, 2019

Citation: Narjis Rizvi (2019) Prevalence and Factors Associated with Violence against Women in Pakistan. J Womens Health Gyn 6: 1-3.

\begin{abstract}
Background: Violence against women is multifaceted, and multidimensional global phenomenon; but highly endemic in Pakistan. Gender roles and socio-economic factors put women in subordinate status that makes them prone to all kinds of violence. Violence influences personality, lifestyle, and health; particularly reproductive practices. The current paper aimed to assess the prevalence and factors associated with violence against women in Pakistan.

Methods: Secondary data analysis of the Pakistan Demographic and Health Survey (PDHS) 2012-13 was done. A total of $\mathrm{n}=2941$ married women between the ages of 15-49 were included; of these 841 were asked about violence. The variables included socio-demographic characteristics, violence, and its typology, fertility and contraceptive use. Data were analyzed using SPSS version 19. Descriptive statistics were run to describe the population socio-demographic characteristics and violence. Binary logistic regression and multivariate model were used to assess the possible association of violence with socio-economic characteristics.
\end{abstract}

Results: Of the 2941 ever-married women of the reproductive age group (15-49 years) from Sindh included in the analysis, $58.35 \%$ were illiterate, $30.09 \%$ were employed workers, $28.24 \%$ were current contraceptive users and $34.70 \%$ ever terminated pregnancy. Of those who were asked about violence $(n=841), 38.34 \%$ reported experiencing any type of violence, however, $58.90 \%$ neither sought help nor informed anyone. On Univariate analysis violence was found to be associated with: women's illiteracy (OR 3.0, 1.7-5.3), poverty (OR 3.0, 2.0-4.7) non-working status (OR 1.8, 1.3-2.5), lack of house ownership (OR 1.7, 1.1-3.0), Husbands' characteristics that were found to be associated with violence against women were illiteracy (OR 2.5, 1.64.0) and skilled manual occupation (OR 2.2, 1.1-4.2). Three factors that remained associated with violence on multivariate analysis were; women's non-working status (OR 1.8, 1.3-2.5) and high parity (OR 1.7, 1.2-2.4) and husbands' education (OR $1.8,1.1-2.5)$.

Conclusion: Violence against women is prevalent in Pakistan; most victims are not reporting or seeking help. Victims of violence are uneducated, unemployed, high parity women who were non-contraceptive users and whose husbands were illiterate. To decrease the magnitude and intensity of violence against women, short and long term promotive to rehabilitative actions are required ranging from establishment of shelters to provide relief to violence victims to structural reforms for improving the status of women to control and prevent violence.

Keywords: Violence; women; gender roles; socio-economic factors; Pakistan

C2019 The Authors. Published by the JScholar under the terms of the Creative Commons Attribution License http://creativecommons.org/licenses/ by/3.0/, which permits unrestricted use, provided the original author and source are credited. 


\section{Introduction}

Across the globe, in all societies, women and girls are subjected to physical, sexual and psychological abuse that cuts across lines of income, class, and culture [1]. The worldwide average of physical and/or sexual intimate partner violence or sexual violence by a non-partner at some point in women's lives is estimated as 35 percent through [2], in some countries this burden is up to 70 percent [3]. Violence against women not only violates women's rights and fundamental freedom, but it also impairs their health particularly sexual and reproductive health.

Although violence against women is a complex multifactorial and multi-dimensional phenomenon; literature, however, attributes it to women's socio-economic positions. Nevertheless, the pervasiveness of violence across class, religion, ethnicity and the urban/ rural divide, strongly indicates towards this being gender-based [4]. Gender-based violence has its roots in a patriarchal social structure in which women are subservient to men, and are viewed as property; many studies have identified gender inequity as one of the key determinants of violence against women [5]. Low socio-economic status intertwined with patriarchal culture put the women in a subordinate position that have repercussions for their three important spaces namely; bodily personal and cognitive [6].

On the same premise, Pakistan provides a conducive environment for violence against women; the country ranks extremely low in Gender Development Index (GDI) $\left(125^{\text {th }}\right.$ out of 169 countries) [7], and Gender Empowerment Measurement (GEM) (99 $9^{\text {th }}$ out of 109 countries) [8]. According to an estimate, 70 to 90 percent of Pakistani women are subjected to domestic violence [9]. Pakistani girls and women are far worse off than their global counterparts; women in Pakistan are facing discrimination and inequality in almost every aspect of life [10]. Consequently, Pakistan is reported as the third most dangerous country in the world for women, after Afghanistan and the Democratic Republic of Congo [11]. Approximately 5000 Pakistani women are killed per year from domestic violence, with thousands of others maimed or disabled [12]. Spousal abuse is rarely considered a crime socially unless it takes an extreme form of murder or attempted murder; examples range from driving a woman to suicide or engineering an accident such as the bursting of a kitchen stove [13]. It is important to estimate the magnitude and extent of violence against women in Pakistan through however, what is more, crucial is to find out the role societal practices and context play on the occurrence of violence and its consequences on women's health. The aim of this paper is therefore to determine the socio-cultural, individual and relationship level factors associated with violence against women and the effects of violence on reproductive health, especially contraceptive use.

\section{Material and Methods}

We present results on the secondary data analysis of $\mathrm{Pa}$ kistan Demographic and Health Survey (PDHS) 2012-13. The PDHS survey presents a randomly selected nationally representative sample of all four provinces. The sample from each province is selected through a multistage cluster sampling technique using uniform methodology. We present results from the province of Sindh only.

The PDHS survey mainly collects information related to housing conditions; socioeconomic characteristics; education; nutrition; maternal/reproductive, adult and child health; mortality and its causes; knowledge regarding Tuberculosis, Hepatitis and Human Immuno-Deficiency; and healthcare practices [14]. In the 2012-13 PDHS, for the first time, information was also gathered regarding women's empowerment and violence against them.

All married women between the ages of 15-49 ( $n=2941)$ were included in the descriptive analysis. The Socio-Demographic variables included age, gender, education, employment status, occupation of woman and husband, income, possession of house-hold goods, residence in terms of urban/rural, city and province, access to media and age at first marriage. For the determination of the prevalence of violence and the assessment of the possible association of violence with socio-demographic characteristics, only those women were analyzed $(n=841)$ to whom questions about violence were asked. The variables related to violence included types of violence, spousal violence, the experience of physical violence, and violence during pregnancy.

The weighted analysis approach was used to adjust for sampling technique that was in the demographic survey (Multistage Cluster Sampling). Frequency distribution of demographic and socio-economic variables including the age of women, area of residence, education level of women and husband occupation and ethnicity are reported (Table 1). Weighted Simple and Multiple Binary Logistic Regression was used to determine the factors related to violence. In univariate analysis, crude Odds Ratio (OR) with 95\% confidence intervals were reported. All significant variables ( $p$-value $<0.05)$ at the time of univariate analysis or biologically plausible with $\mathrm{p}$-value $<0.2$ were considered eligible for multivariable analysis. In multivariable analysis, Adjusted Odds Ratio (AOR) with 95\% confidence interval were reported. All variables whose $\mathrm{p}$-value were less than 0.05 were considered 
as a factor at a multivariable level to get a parsimonious model. Data were analyzed using SPSS version 19.

\section{Results}

Of 2941 ever-married women of the reproductive age group (15-49 years) from Sindh included in the analysis, 1652 were from urban and 1283 from rural areas. Around two third of these women were between 20-39 years (69.80\%) and more than half had no education at all (58.35\%). One third (35.29\%) of women were working at the time of the survey. The most frequent ethnicity was Sindhi (35.73\%) followed by Urdu speaking (23.12\%) and Punjabi (19.87\%). In terms of wealth index, the major proportion of women were from the poorest $(31.19 \%)$ families followed by the richest (28.61\%). Concerning their husband's characteristics, most (64.70\%) of the husbands had some education and nearly all of them (98.8\%) were working. Of those who were working, nearly half $(45.81 \%)$ of them were manual workers either skilled (23.53\%) or unskilled (22.28\%). Of all the women interviewed, 28.24 percent were current contraceptive users, however, 34.70 percent ever terminated pregnancy (Table-1).

Of these ever-married women of the reproductive age group (15-49 years) from Sindh included in the analysis $(n=2941), 841$ were asked about violence. Of these $(n=841)$, 38.40 percent reported experiencing any type of violence. Physical violence was the commonest (23.53) followed by emotional one (14.81\%); 7.43 percent of women even reported violence during pregnancy. Those who reported experiencing violence, 58.9 percent neither sought help nor informed anyone. Weighted analysis of ever-married women between 15-49 years ever experiencing violence revealed that rural uneducated high parity non-working women belonging to poor families between the ages of 25-39 mostly experienced violence. Husbands of these women were uneducated and skilled manual workers (Table-2).

On Univariate analysis, violence was found to be associated with certain women's characteristics including; lack of education (OR 3.0, 1.7-5.3), poverty (OR 3.0, 2.0-4.7) non-working status (OR 1.8, 1.3-2.5) and lack of house ownership (OR 1.7, 1.13.0). Husbands' characteristics that were found to be associated with violence on women were lack of education (OR 2.5, 1.6-4.0) and skilled manual occupation (OR 2.2, 1.1-4.2) (Table-2). On multivariate analysis three factors that remained associated with violence were; women's non-working status (OR 1.5, 1.1-2.5), and high parity (OR 1.7, 1.2-2.4) and husbands' illiteracy (OR 1.8, 1.3-2.5) (Table-3).

\section{Discussion}

In our study the reported prevalence of any type of violence $(38.40 \%)$ is slightly higher than world average (35.00 \%) [2], same as in Sub-Saharan Africa (38.40) [15] and almost similar to the South-East Asian average (37.7\%) a population-based study conducted in Pakistan has however reported a higher prevalence (57.6 percent) [16]. The high prevalence of violence in the country suggests the need for immediate interventions to serve the immediate needs of violence victims, such as the establishment of specific service delivery points like shelters, safe retreats, and counseling services $[17,18]$. However, to control and prevent violence, structural changes are required to address underlying causes and risk factors of violence. In this regard, Pakistan is a signatory of all international treaties [1] that aim to ensure human rights and minimize violence against women. The Pakistani government has transformed its commitments into national priorities and translated these priorities into legal and policy initiatives. Consequently, several ministries/authorities/institutions have been formed to protect women's rights. These ministries/authorities/institutions have improved the advisory and research role of government institutions about women's rights though, yet however, nearly all gender equality and women empowerment indicators in the country show slow progress [13]. Furthermore, there is a rise in the magnitude, extent, and intensity of violence against Pakistani women during the last decade [19]. The two major reasons for the inability of these institutions to control violence against women are inadequate finances and administrative authority though, however failure to functionally integrate gender into other governmental sectors is also an important gap [4]. To effectively decrease the magnitude of violence against women, institutions mandated to promote gender equity and prevent gender-based violence have to work in close collaboration/coordination with other sectors to mainstream gender in health, education, security, legal and finance.

The current study also found that around 59.90 percent of Pakistani women experiencing violence neither sought care nor informed anyone. Even globally, the same proportion of women do not seek help and those who do, most look to family and friends and less than 10 percent appeal to formal institutions and mechanisms [3]. In Pakistan, laws are though protecting women's rights [20], women are still not seeking legal help possibly because of the unfair punishment received by women who claimed legal rights. These punishments were given by existing parallel justice system like Jirga and panchayat; these structures prescribe tribal/community norms that consider that violence against women is a private matter, and women's demand for in- 
Table 1: Weighted analyses of Basic demographic, Fertility preference characteristics, knowledge and use of contraceptive methods among Ever-married women age 15-49 in Sindh, Pakistan

\begin{tabular}{|c|c|c|}
\hline Variable & Unweight Number $(n=2941)$ & Weighted (\%) \\
\hline \multicolumn{3}{|l|}{ Basic Demographic Information } \\
\hline \multicolumn{3}{|l|}{ Place of Residence } \\
\hline Rural & 1283 & 51.44 \\
\hline Urban & 1658 & 48.56 \\
\hline \multicolumn{3}{|l|}{ Age } \\
\hline $15-19$ & 132 & 4.920 \\
\hline $20-24$ & 452 & 15.410 \\
\hline $25-29$ & 588 & 20.560 \\
\hline $30-34$ & 535 & 18.590 \\
\hline $35-39$ & 470 & 15.480 \\
\hline $40-44$ & 366 & 11.820 \\
\hline $45-49$ & 398 & 13.220 \\
\hline \multicolumn{3}{|l|}{ Education } \\
\hline No education & 1582 & 58.35 \\
\hline Secondary & 519 & 15.77 \\
\hline Higher & 468 & 13.92 \\
\hline Primary & 372 & 11.96 \\
\hline \multicolumn{3}{|l|}{ Working Status \& Occupation } \\
\hline not working & 2015 & 64.71 \\
\hline Agricultural - employee & 231 & 10.34 \\
\hline Skilled manual & 130 & 9.00 \\
\hline Services & 168 & 6.71 \\
\hline Unskilled manual & 300 & 6.00 \\
\hline Professional/technical/managerial & 60 & 2.03 \\
\hline Sales & 21 & 0.64 \\
\hline Household and domestic & 14 & 0.56 \\
\hline Clerical & 02 & 0.09 \\
\hline
\end{tabular}




\begin{tabular}{|c|c|c|}
\hline \multicolumn{3}{|l|}{ Ethnicity } \\
\hline Sindhi & 1060 & 35.73 \\
\hline Urdu & 767 & 23.12 \\
\hline Punjabi/Saraiki & 553 & 19.87 \\
\hline Others & 178 & 12.46 \\
\hline Balochi & 149 & 6.482 \\
\hline Pushto & 65 & 2.326 \\
\hline \multicolumn{3}{|l|}{ Husband's/ Education } \\
\hline No education & 958 & 35.35 \\
\hline Higher Secondary & 805 & 24.20 \\
\hline Secondary & 705 & 23.87 \\
\hline Primary & 460 & 16.11 \\
\hline Don't know & 07 & 0.27 \\
\hline \multicolumn{3}{|l|}{ Husband's/Occupation } \\
\hline Skilled manual & 644 & 23.53 \\
\hline Unskilled manual & 655 & 22.28 \\
\hline Sales & 583 & 16.82 \\
\hline Agricultural - employee & 391 & 15.40 \\
\hline Services & 300 & 10.11 \\
\hline Professional/technical/managerial & 246 & 8.12 \\
\hline Clerical & 63 & 1.96 \\
\hline Did not work & 41 & 1.24 \\
\hline Agricultural - self-employed & 12 & 0.37 \\
\hline Household and domestic & 05 & 0.12 \\
\hline \multicolumn{3}{|l|}{ Number of Children $\leq 5$ years } \\
\hline $0-2$ & 2445 & 82.72 \\
\hline$\geq 3$ & 496 & 17.28 \\
\hline
\end{tabular}




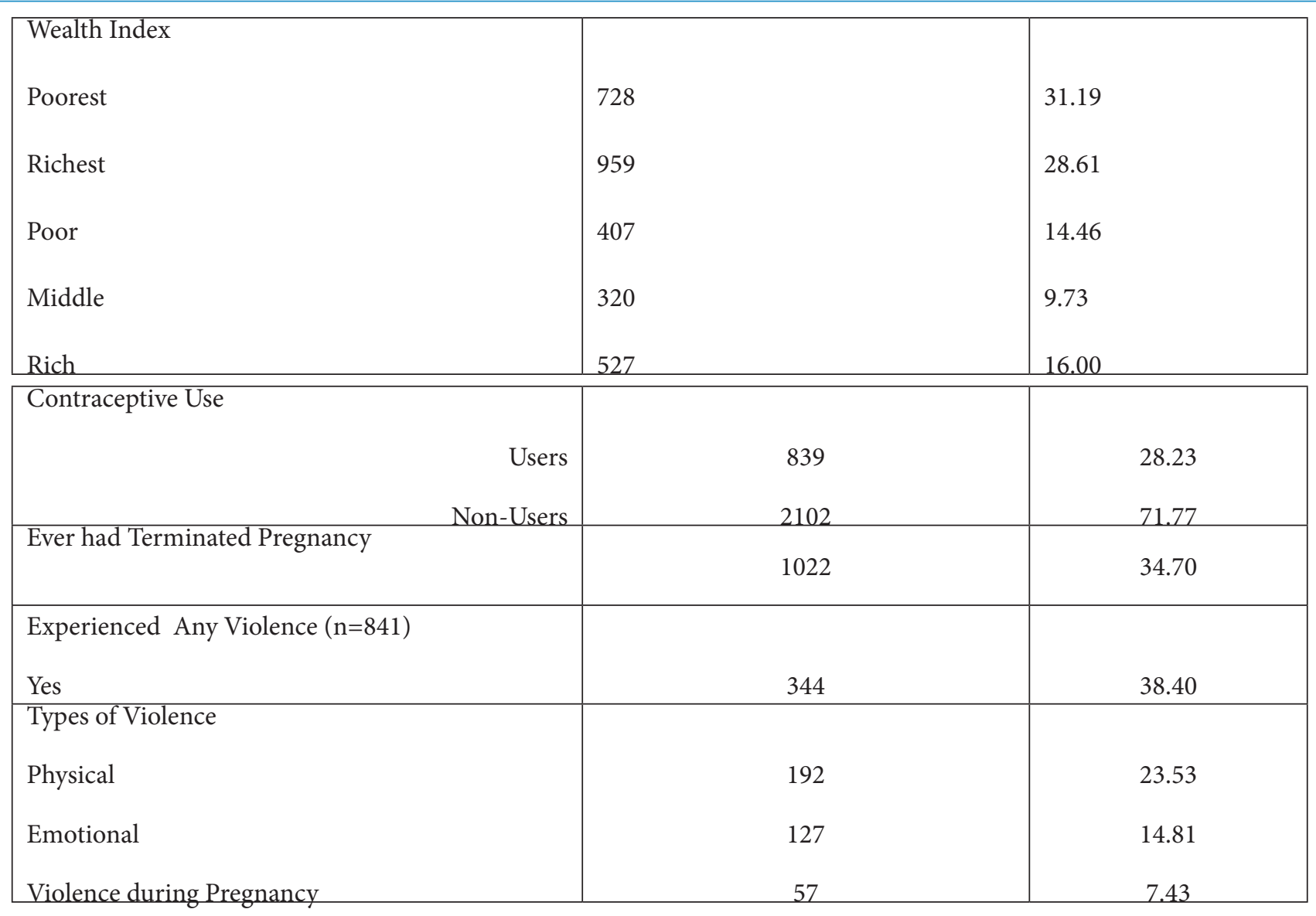

Table-2: Univariable analyses of Currently Married Women of Reproductive Age (15-49) in Sindh, Pakistan ( $\mathrm{n}=841$ )

\begin{tabular}{|c|c|c|c|}
\hline Variables & $\begin{array}{l}\text { Experienced any vi- } \\
\text { olence }(n=344)\end{array}$ & $\begin{array}{l}\text { Didn't Experience any vi- } \\
\text { olence }(n=497)\end{array}$ & OR(95\% CIs) \\
\hline & \multicolumn{2}{|l|}{ Weighted (\%) } & \\
\hline \multicolumn{4}{|l|}{ Age } \\
\hline $15-29$ & 40.00 & 39.00 & $1.3(0.9-2.0)$ \\
\hline $30-39$ & 38.00 & 33.60 & $1.4(1.0-2.1)$ \\
\hline $40-49$ & 22.00 & 27.50 & 1 \\
\hline \multicolumn{4}{|l|}{${ }^{\star}$ Number of Children Ever Born } \\
\hline $1-2$ & 20.00 & 29.00 & 1 \\
\hline 0 & 13.00 & 12.00 & $1.5(0.9-2.6)$ \\
\hline$\geq 3$ & 67.50 & 59.00 & $1.7(1.2-2.4)$ \\
\hline \multicolumn{4}{|l|}{ Current Marital Status } \\
\hline Married & 97.0 & 96.00 & $1.4(0.7-2.8)$ \\
\hline Widowed/Divorced/No longer living together & 3.00 & 4.00 & 1 \\
\hline
\end{tabular}




\begin{tabular}{|c|c|c|c|}
\hline \multicolumn{4}{|l|}{${ }^{*}$ Ethnicity } \\
\hline Urdu & 19.30 & 29.00 & 1 \\
\hline Punjabi/Saraiki & 22.00 & 16.30 & $2.0(1.3-3.2)$ \\
\hline Sindhi & 35.41 & 36.70 & $1.5(0.9-2.4)$ \\
\hline Pushto & 2.00 & 2.12 & $1.4(0.5-4.0)$ \\
\hline Balochi & 8.61 & 4.65 & $2.8(1.7-4.7)$ \\
\hline Others & 13.00 & 11.30 & $1.7(1.0-2.9)$ \\
\hline \multicolumn{4}{|l|}{ * Respondent's Education } \\
\hline No education & 65.40 & 53.30 & $3.0(1.7-5.3)$ \\
\hline Primary/Secondary & 27.00 & 28.42 & $2.3(1.3-4.0)$ \\
\hline Higher & 7.50 & 18.30 & 1 \\
\hline \multicolumn{4}{|l|}{${ }^{*}$ Respondent’s Working Status } \\
\hline Working & 54.00 & 67.00 & 1 \\
\hline Not Working & 46.00 & 33.00 & $1.8(1.3-2.5)$ \\
\hline \multicolumn{4}{|l|}{${ }^{\star}$ Husband's Education } \\
\hline No education & 44.60 & 30.50 & $2.5(1.6-4.0)$ \\
\hline Primary/Secondary & 38.50 & 40.50 & $1.6(1.1-2.5)$ \\
\hline Higher & 17.00 & 29.00 & 1 \\
\hline \multicolumn{4}{|l|}{${ }^{\star}$ Husband's Occupation $(\boldsymbol{n}=\mathbf{8 3 0})$} \\
\hline Professional/technical/managerial & 6.50 & 9.70 & 1 \\
\hline Clerical/Sales/ Services & 22.60 & 32.00 & $1.1(0.6-2.0)$ \\
\hline $\begin{array}{l}\text { Agricultural - self-employed or employed/House- } \\
\text { hold and domestic }\end{array}$ & 15.00 & 15.30 & $1.5(0.6-3.4)$ \\
\hline Skilled manual & 31.00 & 21.00 & $2.2(1.1-4.2)$ \\
\hline Unskilled manual & 25.00 & 22.00 & $1.7(0.9-3.4)$ \\
\hline \multicolumn{4}{|l|}{${ }^{\star}$ Wealth Index } \\
\hline Poorest & 57.00 & 40.00 & $3.0(2.0-4.7)$ \\
\hline Middle & 8.62 & 10.20 & $1.8(1.1-3.0)$ \\
\hline Rich & 18.24 & 15.70 & $2.5(1.5-4.0)$ \\
\hline Richest & 16.20 & 34.35 & 1 \\
\hline \multicolumn{4}{|l|}{ House Ownership } \\
\hline Owns a House & 8.00 & 13.08 . & 1 \\
\hline Does not Own & 92.00 & 87.00 & $1.7(1.1-3.0)$ \\
\hline
\end{tabular}


Table-3: MultivariableWeighted analyses of Married Women of Reproductive Age (15-49) whoever experienced any type of violence in Sindh, Pakistan $(\mathrm{n}=841)$.

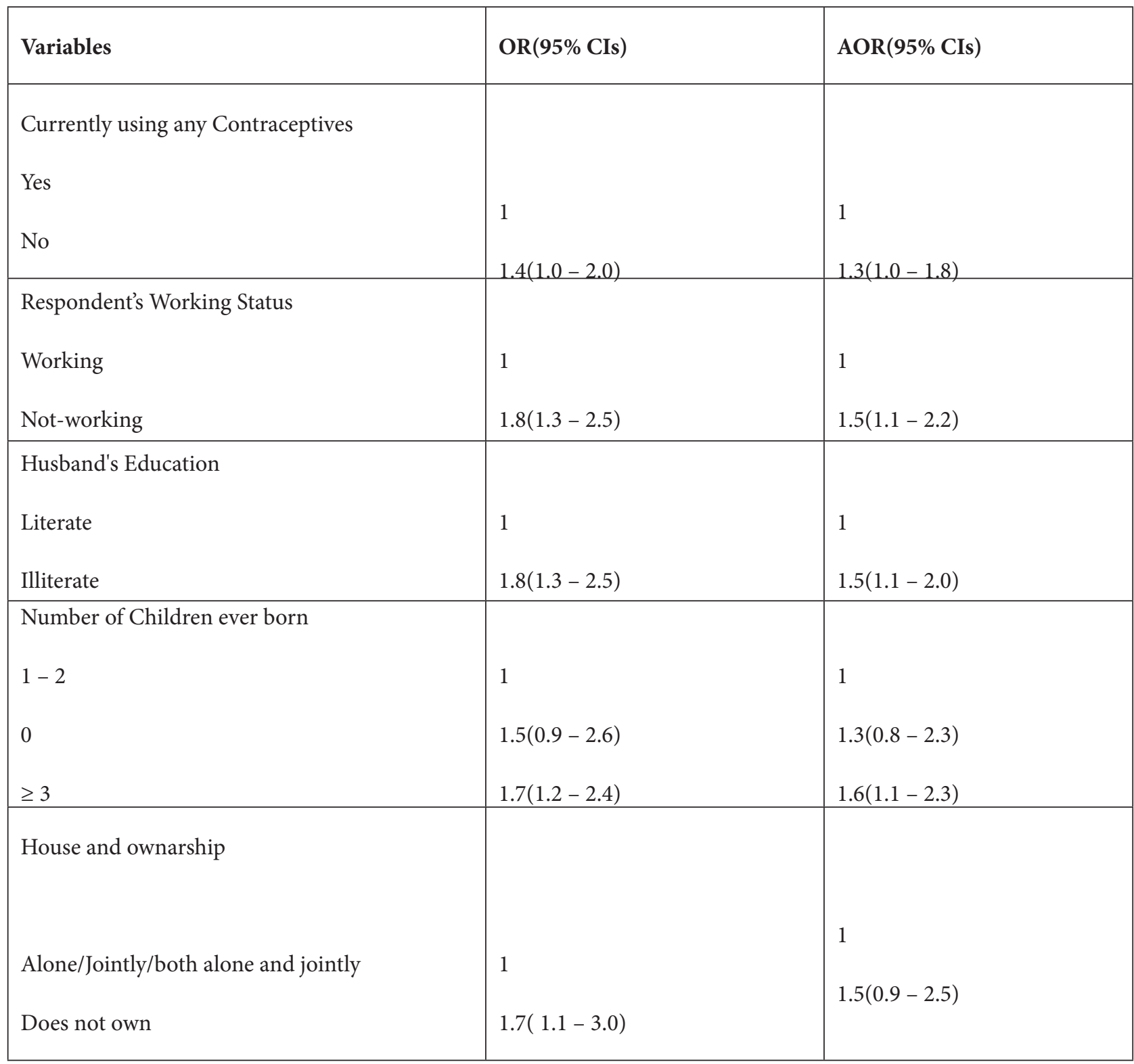

dividual rights is a violation against the norms [21]. Within this dogmatic society, adequate implementation of laws alone would not be enough, legal assistance needs to be brought closer to women to facilitate them in seeking legal support at the time of need; establishment of national and district level legal assistance centers could be an option [22]. Women's lack of knowledge about their rights and recourse options is another important reason for women's silence over abuse and for not seeking legal help; lack of knowledge in fact is a fallout of absence/limited education and economic opportunities for them [10]. Short-term training programs can make women aware of their constitutional and religious rights, and equip them with competencies to demand these.
Our study found a higher occurrence of violence among non-working women. Other studies also have found a similar relationship between violence against women and their earning $[23,24]$, financial independence [25] and socio-economic positions $[26,27]$. This suggests the need for enhancement of educational and employment opportunities to help reduce violence against women. In Pakistan and other similar countries, rural women spend a great deal of time and energy in unpaid domestic and fieldwork [28] establishment of cottage industries can help rural women earn and raise their status [29]. However, it is not that simple! Women's role and hence scope of work in the society is determined by cultural norms in general and the male perception about women's role in particular. Behavior Change Communications are therefore crucial to gender sensitize com- 
munities and create gender equity in societies so that women are not considered inferior anymore and given equal education and employment opportunities. This will enable women to get an education, employment and hence protect them from violence.

We also found that women experiencing violence were low contraceptive users as also shown in studies from developed and developing countries for several decades [30-34]. Various researchers have identified a possible reason for the relationship between violence and non use of contraceptive including; women's lack of control over her reproductive functions [35-38], fear of abuse among women that make birth control negotiation difficult $[33,35,39-43]$ and use of verbal and physical violence by men to force women to become pregnant [44-46]. Studies have also shown that non-use of contraception results into unintended pregnancies which are more than twice as likely to end in abortion [15, 33, 34, 44, 47-50]. Moreover, both population- and clinic-based studies have reported a direct relationship between unintended pregnancy and physical violence [30, 31, 34, 41, 45, 51-60]. Similarly, in our study, 33.70 percent terminated pregnancy a least once. Since, women frequently take long time for deciding to leave violent relationships $[39,61,62]$, it is important to guide these women to plan their pregnancies. A positive move in this regard is the recognition of violence against women a major public health problem [63] and hence the recommendation of professional bodies to address this issue in clinical practice through screening patients populations[64, 65]. For this, clinical protocols including family planning counseling guidelines should include a section on violence. Experience of violence can be used as a risk marker to identify women at risk of contraceptive non-use, unintended pregnancy, and abortion. Training of healthcare providers will also be required to interact and counsel this vulnerable group since counseling on this sensitive personal issue would be challenging. Within the Pakistani milieu where clinical protocols and guidelines are not universally available and healthcare providers rarely counsel, efforts are needed to equip women with communication, negotiation and decision making skills especially with regard to reproductive health decision making.

The current paper is based on the secondary analyses of the data of the Pakistan Demographic and Health survey 2012. Being a large national survey the sample size was adequate to conduct univariate and multivariate analysis; the sample was representative of the target population and findings had greater validity and generalizability $[66,67]$. Availability of substantial breath of information on socio-economic variables of the respondents and their families helped in determining the associ- ation of these factors within violence against women. However, the study could not identify any novel locally prevailing context and culture-specific factors that might be contributing in violence against women since the data were collected for some other purpose; one of the limitations of the secondary data analysis method approach [68]. Moreover, since the paper has been based only on a cross-sectional survey it could not found out why the trend of violence against women has risen during the last decade and how the factors such as women's unemployment work and husband's education are contributing in violence against women. Also, the sample was restricted to one province. Future research using a mixed-method approach may be required to answer these questions.

\section{Conclusion}

We conclude that despite the government's commitments and extensive efforts, violence against women is still prevalent in Pakistan and women are not reporting or seeking help. Most common victims of violence are uneducated, unemployed, high parity women who were nonusers of contraceptives and whose husbands were illiterate and skilled workers. To relief violence victims and also decrease the occurrence of violence against women, short and long term promotive to rehabilitative actions are required. Curative and rehabilitative short and medium-term actions could be: inclusion of a section on violence in gynecological/obstetric/family planning protocols/guidelines to identify and guide women at risk of non-use of contraceptives, unintended pregnancies and unsafe abortions; training of healthcare providers to communicate, counsel and guide violence victims; establishment of shelters, safe retreats and counselling services; creation of national, provincial and district level legal assistance centers; building public pressure by human rights groups and civil society to ensure effective implementation of law against perpetrators of violence against women; and review and revision of laws.

Promotive and preventive long-term actions include:attainment of gender equity through gender mainstreaming in all the sectors such as health, education, security, or other services; effective coordination and collaboration between government and non-governmental organization working for women's rights and protection; designing and implementation of socially acceptable and culturally appropriate behavior change communication interventions to modify behaviors, practices and attitudes towards women and role of women; sensitization and awareness-raising about gender and gender roles, women's rights and mechanisms to demand these rights; trainings to equip women 
with communication, negotiation and decision making skills; and enhancement of educational and employment opportunities for women such as establishment of cottage and other small industries.

\section{Authors' contributions}

The study was conceptualized by NR and drafted by NR. All authors have read and approved the final version of the manuscript.

\section{Acknowledgments}

Authors would like to acknowledge Mr. Iqbal Azam, who has contributed to quantitative data analysis.

\section{References}

1. (1995) Nations U. Beijing Declaration and Platform for Action.

2. (2013) Organization WH. Global and regional estimates of violence against women. Prevalence and health effects of intimate partner violence and non-partner sexual violence. Global and regional estimates of violence against women prevalence and health effects of intimate partner violence and nonpartner sexual violence.

3. (2015) Nations U. The World's Women 2015. Trends and Statistics. New York: United Nations, Department of Economic and Social Affairs, Statistics Division.

4. Parveen R (2011) Gender-based violence in PakistanA scoping study. Aurat Foundation.

5. (2016) Organization WH. INSPIRE seven strategies for ending violence against children: World Health Organization.

6. Burlap KK (2004) The theory of mindful space: Identifying, understanding, and preventing violence. Affilia19: 85-98.

7. (2009)Programme UND. Human Development Report 2009: Human Development on the Move: UN.

8. Klugman J (2010) Human Development Report 201020th Anniversary Edition. The Real Wealth of Nations: Pathways to Human Development.

9. Gosselin DK (2014) Heavy hands: An introduction to the crimes of intimate and family violence: Pearson.

10. Babur ZU. (2007) Violence Against Women in Pakistan: Current realities and strategies for change. Unpublished dissertation for Masters of Arts Degree in Peace and Conflict Studies, European University Center for Peace Studies Stadtschlaining/ Burg, Austria)

11. Anderson Laurie M, Adeney Kathryn L, Shinn C, Safranek S, Buckner-Brown J, et al. (2015) Community coalition- driven interventions to reduce health disparities among racial and ethnic minority populations. Cochrane Database of Systematic Reviews [Internet].

12. Jackson NA (2007) Encyclopedia of domestic violence: Routledge.

13. (2002) Pakistan HRCo. State of Human Rights in Pakistan: Human Rights Commission of Pakistan.

14. (2013) Pakistan Demographic and Health Survey 2012-

2013. Islamabad National Institute of Population Studies (NIPS),

15. Alio AP, Daley EM, Nana PN, Duan J, Salihu HM (2009) Intimate partner violence and contraception use among women in Sub-Saharan Africa. International Journal of Gynecology \& Obstetrics 107: 35-38.

16. Ali TS, Asad N, Mogren I, Krantz G (2011) Intimate partner violence in urban Pakistan: prevalence, frequency, and risk factors. International journal of women's health 3:105.

17. Jacoby M, Gorenflo D, Black E, Wunderlich C, Eyler AE (1999) Rapid repeat pregnancy and experiences of interpersonal violence among low-income adolescents. American journal of preventive medicine16: 318-321.

18. Wathen CN, MacMillan HL (2003) Interventions for violence against women: scientific review. Jama 289: 589-600.

19. (2017) Government P. Punjab Gender Parity Report.

20. Perveen R, Hadi R, Moomi Z, Latif R, Jafar G, Muhammad A (2011) Forgotten: Dowry a socially endorsed form of violence in Pakistan. United Nations Entity for Gender Equality and the.

21. Bari F, Khattak SG (2001) Power configurations in public and private arenas: the women's movement response. Power and Civil Society in Pakistan 217.

22. Jabeen F, Jabeen M (2013) Women Empowerment and Socio-Economic Development: A Case Study of Pakistan. European Journal of Business and Social Sciences1: 113-116.

23. Rani M, Bonu S (2009) Attitudes toward wife beating: a cross-country study in Asia. Journal of interpersonal violence. 24: 1371-97.

24. Kocacik F, Kutlar A, Erselcan F (2007) Domestic violence against women: A field study in Turkey. The Social Science Journal 44: 698-720.

25. Kim JC, Watts CH, Hargreaves JR, Ndhlovu LX, Phetla G, Morison LA, et al. (2007) Understanding the impact of a microfinance-based intervention on women's empowerment and the reduction of intimate partner violence in South Africa. American journal of public health 97: 1794-1802.

26. Weaver TL, Sanders CK, Campbell CL, Schnabel M (2009) Development and preliminary psychometric evaluation of the domestic violence-related financial issues scale (DV-FI). 
Journal of Interpersonal Violence 24: 569-585.

27. Barnett OW (2001) Why battered women do not leave, part 2: External inhibiting factors-social support and internal inhibiting factors. Trauma, Violence, \& Abuse 2: 3-35.

28. (1992) Unicef. Situation analysis of children and women in Pakistan. Situation analysis of children and women in $\mathrm{Pa}$ kistan: UNICEF.

29. Jalal-ud-Din M, Khan M (2008) Socio-economic and cultural constraints of women in Pakistan with special reference to Mardan district, NWFP province. Sarhad Journal of Agriculture 24: 485-493.

30. Straus MA, Gelles RJ, Steinmetz SK (2017) Behind closed doors: Violence in the American family: Routledge.

31. Stewart DE, Cecutti A (1993) Physical abuse in pregnancy. CMAJ: Canadian Medical Association Journal 149: 1257. 32. Hillard P (1985) Physical abuse in pregnancy. Obstetrics and Gynecology 66: 185-190.

33. Williams M, Bowen A, Ross M, Timpson S, Pallonen U, Amos C (2008) An investigation of a personal norm of condomuse responsibility among African American crack cocaine smokers. AIDS care 20: 218-227.

34. Campbell JC, Pugh LC, Campbell D, Visscher L (1995) Influence of abuse on pregnancy intention. Women $s$ Health Issues 5: 214-223.

35. Wingood GM, DiClemente RJ, McCree DH, Harrington K, Davies SL (2001) Dating violence and the sexual health of black adolescent females. Pediatrics 107: e72-e.

36. McFarlane J, Malecha A, Watson K, Gist J, Batten E, Hall I, et al. (2005) Intimate partner sexual assault against women: frequency, health consequences, and treatment outcomes. Obstetrics \& Gynecology 105: 99-108.

37. Breiding MJ, Black MC, Ryan GW (2008) Prevalence and risk factors of intimate partner violence in eighteen US states/territories, 2005. American journal of preventive medicine. 34: 112-118.

38. Gee RE, Mitra N, Wan F, Chavkin DE, Long JA (2009) Power over parity: intimate partner violence and issues of fertility control. American journal of obstetrics and gynecology 201: 148. e1-. e7.

39. Shrier LA, Pierce JD, Emans SJ, DuRant RH (1998) Gender differences in risk behaviors associated with forced or pressured sex. Archives of pediatrics \& adolescent medicine 152: 57-63.

40. Davila YR, Brackley MH (1999) Mexican and Mexican American women in a battered women's shelter: barriers to condom negotiation for HIV/AIDS prevention. Issues in mental health nursing 20: 333-355.

41. Stephenson R, Koenig MA, Acharya R, Roy TK. (2008)
Domestic violence, contraceptive use, and unwanted pregnancy in rural India. Studies in family planning 39: 177-186.

42. Sales JM, Salazar LF, Wingood GM, DiClemente RJ, Rose E, Crosby RA (2008) The mediating role of partner communication skills on HIV/STD-associated risk behaviors in young African American females with a history of sexual violence. Archives of pediatrics \& adolescent medicine 162: 432438.

43. Teitelman AM, Ratcliffe SJ, Morales-Aleman MM, Sullivan CM (2008) Sexual relationship power, intimate partner violence, and condom use among minority urban girls. Journal of interpersonal violence 23: 1694-1712.

44. Research. CfI (2000) Domestic violence and birth control sabotage: a report from the Teen Parent Project. Chicago 45. Lang DL, Salazar LF, Wingood GM, DiClemente RJ, Mikhail I (2007) Associations between recent gender-based violence and pregnancy, sexually transmitted infections, condom use practices, and negotiation of sexual practices among HIVpositive women. JAIDS Journal of Acquired Immune Deficiency Syndromes 46: 216-221.

46. Miller E, Decker MR, Reed E, Raj A, Hathaway JE, Silverman JG (2007) Male partner pregnancy-promoting behaviors and adolescent partner violence: findings from a qualitative study with adolescent females. Ambulatory Pediatrics 7: 360366.

47. Ellsberg M, Jansen HA, Heise L, Watts CH, GarciaMoreno C (2008) Intimate partner violence and women's physical and mental health in the WHO multi-country study on women's health and domestic violence: an observational study. The Lancet 371: 1165-1172.

48. Howard L, Trevillion K, Khalifeh H, Woodall A, Agnew-Davies R, Feder G (2010) Domestic violence and severe psychiatric disorders: prevalence and interventions. Psychological medicine 40: 881-893.

49. Black MC (2011) Intimate partner violence and adverse health consequences: implications for clinicians. American journal of lifestyle medicine 5: 428-439.

50. Wadhwa PD, Entringer S, Buss C, Lu MC (2011) The contribution of maternal stress to preterm birth: issues and considerations. Clinics in perinatology 38: 351-384.

51. Gazmararian JA, Petersen R, Spitz AM, Goodwin MM, Saltzman LE, Marks JS (2000) Violence and reproductive health: current knowledge and future research directions. Maternal and child health journal 4: 79-84.

52. Dietz PM, Gazmararian JA, Goodwin MM, Bruce FC, Johnson CH, Rochat RW (1997) Delayed entry into prenatal care: effect of physical violence. Obstetrics \& Gynecology 90: 221-224. 
53. Cokkinides VE, Coker AL (1998) Experiencing Physical Violence During Pregnancy: Prevalence and Correlates. Family \& Community Health 20: 19-37.

54. Hathaway JE, Mucci LA, Silverman JG, Brooks DR, Mathews R, Pavlos CA (2000) Health status and health care use of Massachusetts women reporting partner abuse. American journal of preventive medicine19:302-307.

55. Melendez RM, Hoffman S, Exner T, Leu C-S, Ehrhardt AA (2003) Intimate partner violence and safer sex negotiation: effects of a gender-specific intervention. Archives of Sexual Behavior 32: 499-511.

56. Pallitto CC, O'Campo P (2004) The relationship between intimate partner violence and unintended pregnancy: analysis of a national sample from Colombia. International family planning perspectives 165-173.

57. Silverman JG, Gupta J, Decker MR, Kapur N, Raj (2007) Intimate partner violence and unwanted pregnancy, miscarriage, induced abortion, and stillbirth among a national sample of Bangladeshi women. BJOG: An International Journal of Obstetrics \&Gynaecology 114: 1246-1252.

58. Cripe SM, Sanchez SE, Perales MT, Lam N, Garcia P, Williams MA (2008) Association of intimate partner physical and sexual violence with unintended pregnancy among pregnant women in Peru. International Journal of Gynecology \& Obstetrics 100: 104-108.

59. Gao W, Paterson J, Carter S, Iusitini L (2008) Intimate partner violence and unplanned pregnancy in the Pacific Islands Families Study. International Journal of Gynecology \& Obstetrics 100: 109-115.

60. O'donnell L, Agronick G, Duran R, Myint-U A, Stueve A (2009) Intimate partner violence among economically disadvantaged young adult women: Associations with adolescent risktaking and pregnancy experiences. Perspectives on Sexual and Reproductive Health 4: 84-91.

61. Ferraro KJ, Johnson JM (1983) How women experience battering: The process of victimization. Social Problems. 30: 32539.

62. Herbert TB, Silver RC, Ellard JH (1991) Coping with an abusive relationship: I. How and why do women stay? Journal of Marriage and the Family 311-25.

63. Services H (2000) Healthy People 2010: Objectives for improving health (Part B: Focus areas 15-28). Appendices: US Department of Health and Human Services.

64. Women P, Yawn B, Yawn R, Uden D (1992) American Medical Association diagnostic and treatment guidelines on domestic violence. Archives of Family Medicine 1:39.
65. Helton A (1987) Protocol of care for the battered woman: Prevention of battering during pregnancy. New York: March of Dimes Birth Defects Foundation.

66. Smith AK, Ayanian JZ, Covinsky KE, Landon BE, McCarthy EP, Wee CC, et al. (2011) Conducting high-value secondary dataset analysis: an introductory guide and resources. Journal of general internal medicine 26: 920-929.

67. Smith E, Smith Jr J (2008) Using secondary data in educational and social research: McGraw-Hill Education (UK).

68. Boslaugh S (2007) Secondary data sources for public health: A practical guide: Cambridge University Press.

Submit your manuscript to a JScholar journal and benefit from:

- Convenient online submission

ฯ Rigorous peer review

ๆ Immediate publication on acceptance

- Open access: articles freely available online

व High visibility within the field

ब Better discount for your subsequent articles

Submit your manuscript at http://www.jscholaronline.org/submit-manuscript.php 